\section{PERCEIVED SOCIAL SUPPORT, DEPRESSION AND INSOMNIA AMONG NURSING STAFFS DURING COVID-19}

KEY WORDS: Perceived Social Support, Depression, Insomnia, Nursing staffs and COVID-19.

\section{Inthumathi S.R*}

\section{B. Sudhakaran Dr. V. Smitha Ruckmani}

M.Phil. Clinical Psychology (Final Year), Institute of Mental Health, Chennai, India. *Corresponding Author

Assistant Professor, Institute of Mental Health, Chennai, India.

Associate Professor, Institute of Mental Health, Chennai, India.

Coronavirus disease (COVID-19) is affecting the mental health of people especially the frontline health care workers. Frontline professionals might experience sleep disturbances due to work pressure, stress, anxiety, depression and various other psychological factors. Social support plays a protective role in preventing depression and insomnia among frontline health care professionals. Thus, this study focused on "Perceived Social Support, Depression and Insomnia among Nursing Staffs during COVID-19". Objectives of the study is to explore the levels of depression and insomnia among nursing staffs during the pandemic situation and in finding the relationship between Perceived Social Support, Depression and Insomnia among Nursing Staffs during COVID-19.

The hypothesis of the current study is that there will be a significant relationship between Perceived Social Support and Depression among nursing staffs, there will be a significant relationship between Perceived Social Support and insomnia among nursing staffs and there will be a significant relationship between Depression and Insomnia among nursing staffs. Nature of the study was quantitative and purposive sampling technique was used to collect data. Data was collected through Google forms around Chennai using the Multidimensional Scale of Perceived Social Support, Patient Health Questionnaire-9 and Athens Insomnia Scale from a sample of 51 nursing staffs. Data were analysed using Pearson's Coefficient of Correlation through SPSS Software. Results showed that there is a significant negative relationship between perceived social support and depression. There is no statistically significant relationship between perceived social support and insomnia. There is a significant positive relationship between depression and insomnia. The present study gave insight about the importance of social support especially during the pandemic situation. Intervention for depression and insomnia are recommended in the phase of the current pandemic.

\section{INTRODUCTION}

Psychological health among health care workers has become a major concern since the COVID-19 outbreak. The COVID-19 pandemic brought an immense loss to human life around the world and led to great challenge to doctors, scientists and front end warriors. Since it started in December 2019 in the Hubei province of China, Corona Virus is still showing its diverse effects on human life both locally and internationally (Li et al., 2020). The novel Corona virus has been declared as public health emergency by the WHO and considered pandemic (WHO, 2020). Although the adverse effects of it, health care workers and doctors remain struggling to cope up with the virus and treatment for it. The novel Corona virus affected hundreds of thousands of people who are sick and dying due to the cause of it. Some of the common symptoms of this viral infection are cold, fever, cough, bone pain and respiratory issues leading to pneumonia. Vaccines are on the verge of availability showing positive sign in research and development.

India has inadequate amount of health care workers because of the population at the ratio of 1 per 1,445 Indians which is nothing but short of WHOs prescribed norms of 1 per 1000 people. In Bihar, single doctor is being visited by 28,391 people. UP is ranked $2^{\text {nd }}$ with 19,962 patients per Doctor followed by Jharkhand (18,518), Madhya Pradesh $(16,996)$, Chhattisgarh $(15,916)$ and Karnataka $(13,556)$. A government doctor in India on an average attends 11,082 patients more than What World Health Organization recommends i.e. 10 times more.

Nurses are part of health care workers in the society, too-the COVID-19 pandemic has rapidly disrupted their everyday lives. Findings suggest health care workers are susceptible to various health consequences due to the COVID-19 pandemic. For those with COVID-19 infections, the most common symptoms were fever and cough, which were similar to those seen in the community.

\section{Risk Factors}

Some of the risk factors existed in the health sector has increased due to this COVID -19 pandemic are long shift hours, working in case sensitive department, inadequate amount of PPE kit, diagnosed family personnel's, hand washing technique, uncleanliness, improper infection control. Moreover, long time usage of PPE leading to skin damage, with nasal bridge opening being the most common problem. Battling the novel corona virus lead to psychological distress among frontline workers especially nursing staffs. Researches showing that there are high levels of depression, stress, anxiety, fear, insomnia and PTSD in the health care workers. Furthermore, most exposed and affected population to this pandemic are nurses who work and treat the covid 19 patients in the hospitals. They are suffering with intense physical health issues, mental issues and social issues such as fatigue, stress, anxiety (Shaukat, Ali, \& Razzak, 2020), they are more prone to get the virus; they been put themselves under biosecurity measures of constant medical check-up, usage of PPE kit and isolation practices; there is a constant stress and tension between patients and staff; stigmatization of health care workers who were exposed to Covid patients (International Federation of Red Cross and Red Crescent Societies, 2020), Loss of loved ones, self-isolation and home quarantine, and changes in usual work routines, contamination fears, the closure of institutions and schools, subtle rumour about the pandemic and loss of capital for Government (Javadi et al., 2020), Uncertain situations lead to stress and anxiety (Shanafelt et al.,2020).

There will be more stress around the frontline workers if there is a high demands in work (heavy workload, time pressure, periods of intense concentration) but there is low motivation persists among health care workers, Immunity levels across people tends to get low when the level of stress is high(Segerstrom and Miller, 2004), Constant inquiries with staffs, exhaustive working hours, deprivation of sleep, fear and emotional disturbances( $\mathrm{Li}$ et al., 2020), There is no 
awareness among staffs regarding home quarantine if they are sick or if they can work from home. (Beckman et al., 2020), Changes in the work routine, Feelings of danger, isolation, concern about family members health and friend's health, feeling vulnerable (Lai et al., 2020) and past history of mental illness or traumatic experience (Mental Health Foundation, 2020; Cited in Tomlin, Dalgleish-Warburton, \& Lamph, 2020)

During this COVID-19 outbreak, they are additionally experiencing more fear and stress. Specifically practicing nurses been put on long hours and they were not even provided with mental and emotional support (Veenema \& Meyer, 2020). Because of the lack of knowledge, exhaustive and tiring work, they find it difficult to provide proper care and effort for patients leading to negative emotions and trauma (Sun et al., 2020). So, WHO recommends special supportive care for nurses to help them to be emotionally strong and to improve their mental health (cited in Schutz \& Shattell, 2020).

\section{Impact Of Sleep Disturbances}

A sound sleep plays a vital part in an individual's health. Getting proper rest makes a person to protect his mental health, quality of life and physical wellbeing. Inadequate sleep causes problems with attention and focus, emotional control, decision making and remembering things and coping with stressful situations. The main problem is having a slower reaction time and being lazy. This may lead to lack of concentration and resilience. This may lead to drastic change in working environment. Some of the previous studies show that front line workers may develop health issues and mental issues because of anxiety, depressive symptoms, insomnia, anger and fear.

\section{Social Support}

The term social support often appears in discussions of relationships. Social support means having friends and other people, including family, to turn to in times of need or crisis to give you a broader focus and positive self-image. It enhance quality of life and provides a buffer against adverse life events. Social support refers to the fundamental experience that people need to stay healthy both physically and mentally, to get proper aid and comfort, and to integrate morally and behaviorally into the group or society at hand. (Schwarzer, C., Buchwald, P, 2004). Albrecht and Adelman define social support as verbal and nonverbal communication between recipients and providers that reduces uncertainty about the situation, the self, the other, or the relationship and function to enhance a perceptions of personal control in one's experience. In the case of social support people should look for actual support and perceived support. Actual support is the support an individual receive on what is said, what is given, and what is done for that individual. Perceived support is the individual's belief that social support is available, is generally considered positive and negative, and provides what is considered needed by that individual (Norris \& Kaniasty, 1996).

\section{Review of Literature}

A research study surveyed 1257 healthcare professionals in 34 clinics in China. The rates of psychological stress were found to be higher: depression (50.4\%), anxiety (44.6\%), insomnia (34\%), and general psychological distress (71.5\%) (Tomlin et al., 2020). Frontline healthcare professionals, females, Nursing staffs, and those working in Wuhan, and staffs who were working with patients directly were more likely to have "severe" scores on these outcomes than other health care workers (Lai et al., 2020).

Spoorthy, Pratapa \& Mahantc conducted a study on the mental health problems faced by healthcare professionals due to the COVID-19 pandemic and they found that demographic variables like gender, age, occupation, department of work, place where they work, and psychological variables like self- efficacy, poor social support were related with increased insomnia, stress, depressive and anxiety symptoms in Health Care Workers. COVID-19 could be a separate risk factor for stress in health-care workers, according to the existing evidence (Spoorthy, Pratapa \& Mahantc, 2020).

In January and February 2020, Xiao et al. (2020) conducted a study in China on the Effects of Social Support on Sleep Quality of Medical Staff Treating Patients with Coronavirus Disease 2019 (COVID-19). The findings of the study showed that social support levels for the healthcare workers were significantly related to the degree of self-efficacy, sleep quality and stress. Anxiety levels were associated significantly with stress levels that adversely affected selfefficacy and sleep quality. The mediating variables of social support and sleep quality were stress, anxiety, and selfefficacy (Xiao et al.,2020).

A study showed the prevalence of anxiety and depression among the healthcare workers in Nepal during the COVID-19 pandemic. Results showed that health care workers (38\%) have suffered from anxiety and/or depression during covid19 duty (Gupta et al., 2020).

A total of 1242 Wuhan residents suffered from anxiety (27.5\%), depression (29.3\%), sleep disorder (30.0\%), and showed a passive response to the current pandemic (29.8\%). Wuhan residents used passive coping strategies and their psychological health and quality of sleep were significantly reduced during the pandemic (Fu et al., 2020).

A study on the prevalence of depression, anxiety, and insomnia among healthcare workers during the COVID-19 pandemic: A systematic review and meta-analysis. Earlier studies showed the evidences that a significant proportion of health care workers experienced insomnia and mood problems during this current pandemic (Pappa et al., 2020).

Wasim et al., (2020) studied the effect of COVID-19 Pandemic on Mental Wellbeing of Healthcare Workers in Tertiary Care Hospital. The study included 356 health care workers. The participants in insomnia group predominantly showed symptoms of depression, anxiety, and stress than participants in non-insomnia group.Nursing staffs, healthcare workers and paramedics who were working in isolation/ intensive care units showed significant level of insomnia.

Wang et al., (2020) studied Sleep Disturbances and Psychological Profiles of Medical Staff and Non-Medical Staff during the Early Outbreak of COVID-19 in Hubei Province, China. The study showed that frontline healthcare workers are more prone to sleep disturbances than non-frontline healthcare workers but anxiety and depression were prevalent in both groups.

In a cross-sectional research study, Dong et al. (2020) looked at the social psychological effect of the COVID-19 pandemic on medical workers in China. During the COVID-19 pandemic, about a fifth of medical personnel had psychological issues. Worrying about their physical health, having close COVID-19 contaminated friends, and relationship problems in the family all contributed to the psychological effects of stressful events.

During the COVID-19 pandemic, Labrague published a systematic analysis of quantitative studies on psychological resilience, coping behaviors, and social support among healthcare workers. Healthcare staffs were found to have moderate to high psychological resilience and used problem-focused coping (e.g., seeking social help, praying) as well as emotion-focused coping (e.g., engaging in diversionary activities) to cope with the stress caused by the coronavirus pandemic. Coping behaviors, social support and psychological resilience were positively related with 
psychological and mental health effects (Labrague, 2020).

\section{Need For The Study}

Covid-19 has created a huge impact on people's life especially among the health care workers as it affects the physical and psychological health of an individual.

This study is aimed at highlighting the importance of social support, understanding the level of depression and sleep quality among the nursing staffs doing Covid duty thereby, the findings of the study shall contribute in framing the necessary intervention to manage mental health outcomes among nursing staffs who are on duty during the covid-19 pandemic. There aren't many studies conducted in the Indian context so in order to bridge the gap, the present study on Perceived social support, Depression and Insomnia among nursing staffs during COVID-19 was carried out.

\section{METHOD.}

Research design. The exploratory research design was adopted for the study.

\section{Aim.}

The study aims to find out the relationship between Perceived Social Support, Depression and Insomnia among Nursing Staffs during COVID-19.

\section{Objective.}

To find out the relationship between Perceived social support and Depression.

To find out the relationship between Perceived social support and Insomnia.

To find out the relationship between Depression and Insomnia.

\section{Hypothesis.}

There will be a significant relationship between Perceived social support and Depression.

There will be a significant relationship between Perceived social support and Insomnia.

There will be a significant relationship between Depression and Insomnia.

\section{Sample Characteristics.}

Participants were nursing staffs between ages of 21 years to 60 years. A total of 51 nursing staffs working in a hospital and health care setting at Chennai were included in the study, so as to fulfil the inclusion and exclusion criteria. Out of the 51 participants, 39 were females and 12 were males.

Sample selection. The sampling technique used to select the sample was purposive sampling.

\section{Inclusion Criteria.}

Nursing staffs who are willing to participate in the study and those who signed the informed consent.

Nursing staffs working in hospital or health care setting during the Covid 19 pandemic.

\section{Exclusion Criteria.}

Nursing staffs who are not willing and agreed to participate in the study.

Nursing staffs who do not work in the hospital or health care setting during Covid 19 pandemic.

\section{Tools Used.}

The present research used the following tools for the purpose of measuring the Perceived social support, depression and
Insomnia among Nursing staffs along with a profile and Informed Consent Form.

1. Informed Consent Form. The Informed Consent Form developed by the researcher was used to provide initial information to the samples and in acquiring their consent to participate in the research. The participants were asked to click yes after reading the consent form of the google sheet. 2. Socio-Demographic Status Profile. The profile constructed by the researcher so as to collect demographic information of the samples, including name, age, gender, socio economic status, educational status, marital status, working experience, tested positive for covid-19, needed psychiatric support during pandemic.

3.Multidimensional Scale of Perceived Social Support.

Multidimensional Scale of Perceived Social Support is a standardized self-report developed by Zimet, et.al (1988) that measure perceived social support from three sources such as family, friends and significant others. Perceived social support is the perception of an individual regarding to the family, friends and whole of the society. Social support may be defined as to attain value, respect, care and love from the society (Gurung, 2006). Family is a householder and one or more other persons living in the same household who are related to the householder by birth, marriage, or adoption (census, 1990). Friend is defined as a person that you are fond of, with whom you talk or spend time. Significant other is a person who is important to one's well-being especially a spouse or one in a similar relationship. The scale consist of 12 items and each item is scored on a 7-point likert scale (1, very strongly disagree to 7 , very strongly agree). Higher the score reflect a greater level of perceived social support. It has good internal reliability and test-retest reliability and robust factorial validity (Zimet, Dalhem, Zimet \& Farley, 1988)

4.Athens Insomnia Scale (AIS)

Athens Insomnia Scale (AIS) measures the magnitude of the sleep disturbances. This scale is a psychometric selfassessment tool developed for the measurement of sleep problems on the basis of ICD-10, Insomnia Criteria. There are eight items: the initial five relate to sleep induction, night time awakenings, final waking, quality of sleep and total sleep duration; the final three relate to well-being, functional ability and daytime sleep. In this scale, since last month, the magnitude of the sleep difficulty is calculated based on a 4 point Likert scale. The results ranged from 0 (not being a problem) to 3 (more acute sleep difficulties). A cut-off of 6 was used to differentiate insomniacs from healthy individuals. The scale has been validated in Greek. The internal consistency of 0.89 for the entire scale (Cronbach's Alpha) (Soldatos, Dikeos \& Paparrigopoulos, 2000).

5. Patient Health Questionnaire (PHQ)

The patient health questionnaire used to measure depression (PHQ). it is a self-report tool which consist of 9 items and used commonly in healthcare setting. The total score of each item is from 0 to 3, indicating "depression" in the total score of 5 or more (Kroenke et al.,2010). A total score of 5-9 suggests 'mild depression,' 10-14 'moderate depression' and 15-19 'moderate to severe depression' and $\geq 20$ 'severe depression' (Kroenke et al., 2010). In the primary care study, PHQ-9 has been shown to have good psychometric properties with a Cronbach's of 0.89 and Cronbach's of 0.86 in the obstetricsgynecology study (Spitzer,Williams \& Kroenke, 2001).

\section{Procedure.}

Data was collected from nursing staffs working in hospitals and health care settings in Chennai using password encrypted Google forms and access limited only to the researcher. Form links were sent through email and whatsapp official groups of covid duty. Forms of samples who agreed to take part in the study were taken for research. The questionnaires were in English language that is convenient for the subjects to comprehend the items. The data obtained were entered into a laptop with password protection for further analysis. The scores were calculated and evaluated based on the norms and scoring key given by the author. The 
results were analysed using the SPSS software and the hypothesis verified.

\section{Analysis Of Data}

The data was analysed using 'SPSS' software. Mean and Standard Deviation were used to measure the levels of depression and insomnia among nursing staffs, so as to verify the first hypothesis. Pearson's Product-Moment Correlation was used to find the relationship between perceived social support, depression and insomnia among nursing staffs during Covid-19.

\section{Ethical Considerations.}

Ethical Procedure: The study followed the APA format of ethical consideration. Risks Involved: The participants were informed of the possible risk of emotional disturbances during or post the participation in the study. Consent form: The participants were given a consent form through google forms which will include the details about the study and the author's contact information before participating in the research. Sharing of results: The results of the study were shared with the participants upon request. Harming: No participant was harmed during this study.

\section{RESULTS AND DISCUSSION}

The data has been analysed to verify the hypothesis researched upon and the analysed data has been tabulated and graphically represented.

Table 1 Shows The Frequency And Percentage Of Socio Demographic Variables

\begin{tabular}{|c|c|c|c|c|}
\hline S.no & Variables & & $\begin{array}{l}\text { Frequ } \\
\text { ency }\end{array}$ & \begin{tabular}{|l|} 
Percenta \\
ge
\end{tabular} \\
\hline \multirow{3}{*}{1.} & \multirow{3}{*}{ Age } & $21-30$ & 15 & $29 \%$ \\
\hline & & $31-40$ & 25 & $49 \%$ \\
\hline & & $41-50$ & 11 & $22 \%$ \\
\hline \multirow[t]{2}{*}{2.} & \multirow[t]{2}{*}{ Gender } & Male & 12 & $24 \%$ \\
\hline & & Female & 39 & $76 \%$ \\
\hline \multirow[t]{3}{*}{3.} & \multirow{3}{*}{$\begin{array}{l}\text { Socioeconomic } \\
\text { status }\end{array}$} & Lower class & 2 & $4 \%$ \\
\hline & & Middle class & 48 & $94 \%$ \\
\hline & & Upper class & 1 & $2 \%$ \\
\hline \multirow[t]{3}{*}{4.} & \multirow[t]{3}{*}{ Education } & Undergraduate & 26 & $51 \%$ \\
\hline & & Postgraduate & 25 & $49 \%$ \\
\hline & & Married & 36 & $71 \%$ \\
\hline \multirow[t]{2}{*}{5.} & \multirow[t]{2}{*}{ Marital status } & Unmarried & 15 & $29 \%$ \\
\hline & & Separated & 0 & $0 \%$ \\
\hline \multirow[t]{2}{*}{6.} & \multirow{2}{*}{\begin{tabular}{|l} 
Working \\
experience
\end{tabular}} & Less than 5 years & 15 & $29 \%$ \\
\hline & & More than 5 years & 36 & $71 \%$ \\
\hline \multirow[t]{2}{*}{7.} & \multirow{2}{*}{$\begin{array}{l}\text { Tested positive } \\
\text { for Covid-19 }\end{array}$} & Yes & 15 & $29 \%$ \\
\hline & & No & 36 & $71 \%$ \\
\hline \multirow[t]{2}{*}{8.} & \multirow{2}{*}{$\begin{array}{l}\text { Needed } \\
\text { psychiatric } \\
\text { support in the } \\
\text { covid-19 } \\
\text { pandemic }\end{array}$} & Yes & 19 & $37 \%$ \\
\hline & & No & 32 & $63 \%$ \\
\hline
\end{tabular}

Table 1 Shows the frequency and percentages of socio demographic variables. In this study the sample is comprised of 51 nursing staffs doing covid duty during this current pandemic. Out of 51 nursing staffs, $76 \%$ were females and $24 \%$ were males. The age ranges between 21 to $50.29 \%$ of the samples were between the age range of 21 to $30.49 \%$ of the samples were between the age range of 31 to $40.22 \%$ of the samples were between the age range of 41 to 50 . Majority of the samples were from middle socioeconomic status (94\%).

The sample includes 26 nursing staffs who completed undergraduate course in Nursing which contributes $51 \%$ of the sample and 25 nursing staffs completed postgraduate degree in Nursing that is $49 \%$ of the sample. Marital status of the nursing staffs shows $71 \%$ of the samples are married and $29 \%$ of the samples are unmarried. The working experience of the sample include $29 \%$ (15) have less than five year's experience and $71 \%$ (36) of the samples have more than five year's experience. Nursing staffs who were tested positive for covid- 19 are $29 \%$ and who tested negative for covid- 19 are $71 \%$. when considering psychiatric support needed by the nursing staffs during this pandemic, among the sample $37 \%$ needed psychiatric support and $63 \%$ no needed any psychiatric support during this pandemic.

Table 2 Shows The Prevalence Of Depression And Insomnia Among Nursing Staffs

\begin{tabular}{|l|l|l|l|l|}
\hline S.no & Variables & & N & Percentage \\
\hline \multirow{4}{*}{1.} & \multirow{2}{*}{ Depression } & Minimal & 14 & $27 \%$ \\
\cline { 3 - 5 } & & Mild & 21 & $41 \%$ \\
\cline { 3 - 5 } & & Moderate & 14 & $27 \%$ \\
\cline { 3 - 5 } & & Moderately severe & 2 & $4 \%$ \\
\cline { 3 - 5 } & & Severe & 0 & $0 \%$ \\
\hline 2. & Insomnia & Insomniacs & 26 & $51 \%$ \\
\cline { 3 - 5 } & & Healthy subjects & 25 & $49 \%$ \\
\hline
\end{tabular}

Table 2 Shows the percentage prevalence of depression and insomnia among nursing staffs. In the current study, Depression was categorized into 5 groups based on the norms given and are as follows: minimal were $27 \%$ (14), mild depression was $41 \%(21)$, moderate depression was $27 \%$ (14), moderately severe depression was $4 \%$ (2). There is no severe level of depression present among the sample. The sample consist of $51 \%$ (26) insomniacs and $49 \%$ (25) healthy subjects (non-insomniacs).

Table 3 Shows The Descriptive Statistics Of The Variables

\begin{tabular}{|l|l|l|}
\hline Variables & Mean & SD \\
\hline Perceived social support & 4.09 & 1.46 \\
\hline a) Significant others & 3.87 & 1.78 \\
\hline b) Family & 3.91 & 1.97 \\
\hline c) Friends & 3.74 & 1.59 \\
\hline Depression & 7.13 & 4.41 \\
\hline Insomnia & 6.01 & 3.40 \\
\hline
\end{tabular}

Table 3 shows the Mean and Standard Deviation of the data that were analysed. A total mean of 4.09 was obtained for perceived social support, a mean of 3.87 for significant others, a mean of 3.91 for family, a mean of 3.74 for friends. A total mean of 7.13 was obtained for Depression and a total mean of 6.01 was obtained for Insomnia. The data results suggest that there is a moderate level of social support perceived by the nursing staffs with high prevalence rate of depression and insomnia among the sample.

\section{INSOMNIA}

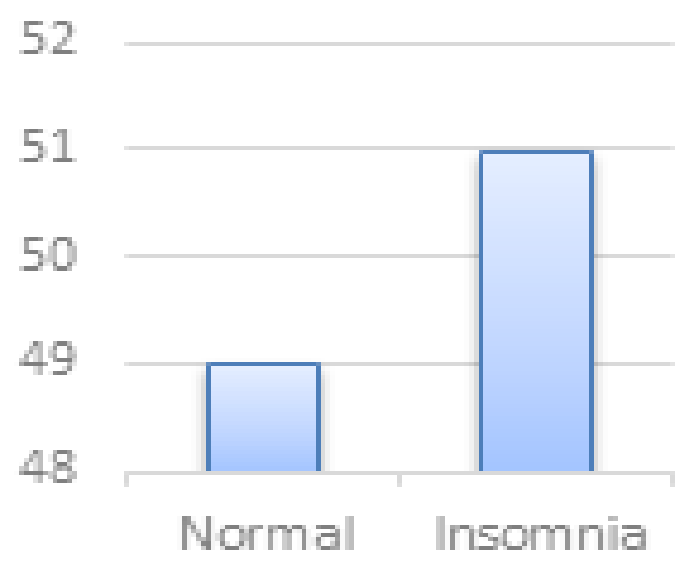


50

40

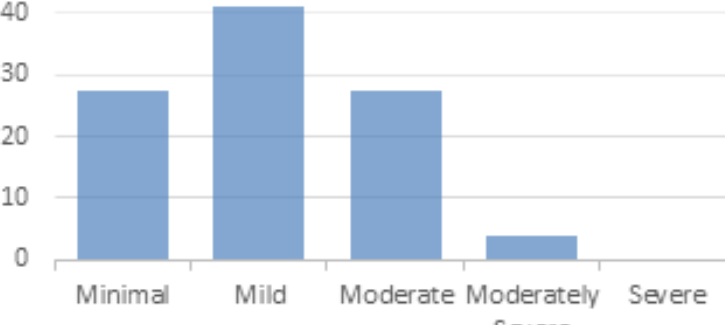

Severe

Depression

Figure 1 Shows The Prevalence Of Depression And Insomnia

Table 4. Pearson's Correlation Coefficient Between The Variables

\begin{tabular}{|l|l|l|}
\hline Variables & Depression & Insomnia \\
\hline Perceived Social Support & $-0.33^{*}$ & -0.03 \\
\hline
\end{tabular}

*Correlation is significant at the 0.05 level

Table 4 shows the relationship between the variables Perceived social support and Depression. Using Pearson's Product-Moment Correlation, it has been found that there is a statistically significant negative relationship between the perceived social support and Depression $(r=-0.33$; $<<.05)$, in other words, if the perceived social support decreases, there will be an increase in depressive symptoms and hence it has led to the alternative hypothesis being accepted. This finding is in accordance with previous research study and the study implies negative association between perceived social support and psychological distress among frontline nurses (Nie et al., 2020). According to Mariani, social support especially family support reduces depressive symptoms (Mariani et al., 2020). According to Wang, both the frontline health care workers and non-frontline healthcare workers experienced anxiety and depressive symptoms during the covid-19 outbreak (Wang et al., 2020).

Table 4 also shows that there is no significant relationship between perceived social support and insomnia. The correlation coefficient of perceived social support and insomnia is -0.03 , which is not significant at 0.05 level. Hence, the alternative hypothesis was rejected. The findings are contradictory to the previous research maybe it is due to small sample size, individual difference, due to other confounding variables such as the data were collected after the situation got much better, data were collected through google forms that might have influenced the results.

Table 5. Pearson's Correlation Coefficient Between Depression And Insomnia

\begin{tabular}{|l|l|}
\hline Variables & Insomnia \\
\hline Depression & $0.46^{* *}$ \\
\hline
\end{tabular}

\section{** Correlation is significant at the 0.01 level}

Table 5 shows the relationship between Depression and Insomnia among the nursing staffs during Covid-19. Using Pearson's Product-Moment Correlation, it has been found that there is a statistically significant positive relationship between depression and insomnia $(r=0.46, \mathrm{p}<.01)$. This shows that higher the depressive symptoms, higher would be the sleep disturbances. This finding was supported by previous study conducted by $\mathrm{Tu}, \mathrm{He} \&$ Zhou where the study found significant relationship between depression and quality of sleep among frontline nurses during covid 19 outbreak in Wuhan, China (Tu, He \& Zhou, 2020). Previous research conducted by Hu et al shows that the prevalence rate of sleep disturbances and depression were high and shows correlation between poor quality of sleep and depression
$(\mathrm{Hu}$, et al, 2020). Some authors argue that Insomnia causes depression (Johnson, Roth \& Breslau, 2006). Whereas some argue that depression is the predicament for insomnia (Ohayon, Caulet \& Lemoine, 1998).

\section{Summary}

Psychological variables such as depression and insomnia were very prominent among health care workers especially among nursing staffs who worked in the hospital or health care setting during the pandemic based on the findings of previous empirical studies. The current research was conducted to identify the relationship between perceived social support, depression and insomnia among nursing staffs who are working in the hospital or health care setting during COVID-19. The objective of the study is to find the relationship between perceived social support and depression, to find out the relationship between perceived social support and insomnia and to find out the relationship between depression and insomnia. Multidimensional scale of perceived social support was used to measure the perceived social support from three sources such as family, friends and significant others, Patient health questionnaire was used to measure depression and Athens insomnia scale was used to measure the severity of sleep disturbances. Sample size of 51 nursing staffs working in the hospital or health care setting for covid duty during COVID-19 pandemic was included in the study. Statistical analysis was analyzed using Pearson correlation of coefficient.

\section{CONCLUSION}

The results of the study showed that there is a significant negative relationship between perceived social support and depression. In other words, When the perceived social support decreases levels of depression are increased. There is no significant relationship between perceived social support and insomnia. There is a significant positive relationship between depression and insomnia i.e., when the levels of depression increase insomnia is increased.

\section{Limitations}

The study was conducted only with a limited sample size due to which results cannot be generalized. The relationship between demographic details and research variables could have been seen. Gender distribution was not equal so, gender differences could not be seen. Covid duty Nursing staffs working in hospital or health care settings during pandemic could have been compared with non-covid duty nursing staffs to see the difference between the groups.

\section{Implications}

The study shall be further carried out using a larger group of samples and the study shall be even more effective, if it is experimental in nature, most specifically incorporation of intervention strategies can be effective in addressing the mental health issues among the nurses and also to find out the effectiveness of the intervention.

\section{REFERENCES}

1. Albrecht, T. L., \& Adelman, M. B. (1984). Social support and life stress. Human communication research, 11 (1), 3-32.

2. Beckman, A. L., Gondi, S., Forman, H. P. (2020). How To Stand Behind Frontline Health Care Workers Fighting Coronavirus Health Affairs. Retrieved from https://www.healthaffairs.org/do/10.1377/hblog20200316.393860/full/

3. Chriscaden, K. (2020). Impact of COVID-19 on people's livelihoods, their health and our food systems. In World Health Organization. Retrieved from https://www.who.int/news/item/13-10-2020-impact-of-covid-19-onpeople's-livelihoods-their-health-and-our-food-systems

4. Doctor-patient ratio in India less than WHO-prescribed norm of 1:1000: Govt. (2019). In ET Healthworld.com. Retrieved from https://health.economictimes. indiatimes.com/news/industry/doctor-patient-ratio-in-india-less-thanwho-prescribed-norm-of-1 1000-govt/72135237 doi: 10.1056/NEJMoa2001316

5. Dong, Z., Ma, J., Hao, Y., Shen, X., Liu, F., Gao, Y., \& Zhang, L. (2020). The social psychological impact of the COVID-19 pandemic on medical staff in China: A cross-sectional study. European Psychiatry, 63(1), E65. doi:10.1192/j.eurpsy. 2020.59

6. Fu, W., Wang, C., Zou, L., Guo, Y., Lu, Z., Yan, S., \& Mao, J. (2020). Psychological health, sleep quality, and coping styles to stress facing the COVID-19 in Wuhan, China. Transl Psychiatry, 10, 225. https://doi.org/10.1038/ s41398020-00913-3 
7. Gupta, A. K., Mehra, A., Niraula, A., Kafle, K., Deo, S. P., Singh, B., Sahoo, S., \& Grover, S. (2020). Prevalence of anxiety and depression among the healthcare workers in Nepal during the COVID-19 pandemic. Asian journal of psychiatry 54,102260.https://doi.org/10.1016/j.ajp.2020.102260

8. Hu, Z., Zhu, X., Kaminga, A. C., Zhu, T., Nie, Y., \& Xu, H. (2020). Association between poor sleep quality and depression symptoms among the elderly in nursing homes in Hunan province, China: a cross-sectional study. BMJ Open, 10,e036401.doi: 10.1136/bmjopen-2019-036401

9. International Federation of Red Cross and Red Crescent Societies. (2020). Mental Health and Psychosocial Support for Staff, Volunteers and Communities in an Outbreak of Novel Coronavirus. Geneva: International Federation of Red Cross and Red Crescent Societies.

10. Javadi, S. M. H., Arian, M., \& Qorbani-Vanajemi, M. (2020). The need for psychosocial interventions to manage the coronavirus crisis. J. Psychiatr. Behav.SCi., 14,el02546. doi: 10.5812/ijpbs. 102546

11. Johnson, E. O., Roth, T. \&, Breslau, N. (2006). The association of insomnia with anxiety disorders and depression: exploration of the direction of risk. $J$ Psychiatr Res, 40(8), 700-8.

12. Kroenke, K., Spitzer, R. L., Williams, J.B. \& Lowe, B. (2010). The patient health questionnaire somatic, anxiety, and depressive symptom scales: a systematic review. Gen. Hosp. Psychiatry, 16(9): 606-613. doi: 10.1046/j.15251497.2001. 016009606.x

13. Labrague,L.J. (2020). Psychological resilience, coping behaviours, and social support among healthcare workers during the COVID-19 pandemic: a systematic review of quantitative studies. medRxiv. doi:https://doi.org/ 10.1101/2020.11.05.20226415

14. Lai J., Ma S., Wang Y., Cai Z., Hu J., Wei N., ... Hu, S. (2020). Factors associated with mental health outcomes among health care workers exposed to coronavirus disease 2019. JAMA network open, 3(3): e203976. doi: 10.1001/jamanetworkopen.2020.3976

15. Lai, J., Ma, S., Wang,Y., Cai, Z., Hu, J.,Wei, N., ... Hu, S. (2020). Factors associated with mental health outcomes among health care workers exposed to coronavirus disease 2019. JAMA Netw. Open. 3, e203976. doi: 10.1001/ jamanetworkopen.2020.3976

16. Li, Q., Guan, X., Wu, P., Wang, X., Zhou, L., Tong, Y., ... Feng, Z. (2020). Early transmission dynamics in Wuhan, China, of novel coronavirus-infected pneumonia.NEnglJMed.382,1199-1207.Doi: 10.1056/NEJMoa2001316

17. Li, W., Yang, Y., Liu, Z.-H., Zhao, Y.-J., Zhang, Q., Zhang, L., ... Xiang, Y.-T. (2020) Progression of mental health services during the COVID-19 outbreak in China.Int.J.Biol.Sci. 1732-1738.10.7150/ijbs. 45120

18. Mariani, R., Renzi, A., Di Trani, M., Trabucchi, G., Danskin, K., and Tambelli, R. (2020). The Impact of Coping Strategies and Perceived Family Support on Depressive and Anxious Symptomatology During the Coronavirus Pandemic (COVID-19) Lockdown. Front. Psychiatry, 11: 587724. 10.3389/fpsyt.2020.587724

19. Maurya, L., \& Goswami, S. (n.d.). India's health workforce crisis. In Down To Earth. Retrieved from https://www.downtoearth.org.in/dte-infographics/ 61322-not_enough_doctors.htm

20. Mental Health Foundation. (2020). Looking After Your Mental Health While Working During The Coronavirus Outbreak [Internet]. Retrieved from https://www.mentalhealth.org.uk/publications/looking-after-y our-mentalhealth-during-coronavirus-outbreak/while-working

21. Nie, A., Su, X., Zhang, S., Guan, W., \& Li, J. (2020). Psychological impact of COVID 19 outbreak on frontline nurses: A cross sectional survey study.Journal of clinical nursing. https://doi.org/10.1111/jocn.15454.10.1111/jocn.15454

22. Norris, F. H., \& Kaniasty, K. (1996). Received and perceived social support in times of stress: A test of the social support deterioration deterrence model. Journal of Personality and Social Psychology, 71,498-511.

23. Ohayon, M. M., Caulet, M., \& Lemoine, P. (1998). Comorbidity of mental and insomnia disorders in the general population. Compr Psychiatry, 39(4), 185-9.

24. Pappa, S., Ntella, V., Giannakas, T., Giannakoulis, V.G., Papoutsi, E., \& Katsaounou, P. (2020). Prevalence of depression, anxiety, and insomnia among healthcare workers during the COVID-19 pandemic: a systematic review and meta-analysis. Brain Behav. Immun., doi: 10.1016/j.bbi. review and meta-analysis. Brain

25. Schutz, V., \& Shattell, M. (2020). Impact of COVID-19: What Does It Mean For Nurses and Health Systems? Journal of Psychosocial Nursing and Mental Health Services, 58(8), 2-3.https://doi.org/10.3928/02793695-20200707-01

26. Schwarzer, C., \& Buchwald, P. (2004). Social support. In C. Spielberger (Ed.) Encyclopedia of appliedpyschology. (pp. 435-441). New York, NY: AcademicPress.

27. Segerstrom, S. C., Miller, G. E. (2004). Psychological stress and the human immune system: a meta-analytic study of 30 years of inquiry. Psychol. Bull., 130,601-630.Doi: 10.1037/0033-2909.130.4.601

28. Shanafelt T., Ripp J., Trockel M. (2020). Understanding and Addressing Sources of Anxiety Among Health Care Professionals During the COVID-19 Pandemic. $J A M A$. Retrieved from a. https://jamanetwork.com/journals/jama/articleabstract $/ 2764380$

29. Shaukat, N., Ali, D. M., \& Razzak, J. (2020). Physical and mental health impacts of COVID-19 on healthcare workers: a scoping review. International Journal of Emergency Medicine, 13,40.doi:10.1186/s12245-020-00299-5

30. Sleep Deprivation and Deficiency (n.d.). In National Heart, Lung and Blood Institute. Retrieved from https://www.nhlbi.nih.gov/health-topics/sleepdeprivation-and-deficiency\#: :text=Sleep $\% 20$ plays $\% 20 \mathrm{a} \%$ 20vital\%20 role, happens\%20while\%20you're\%20sleeping

31. Soldatos, C.R. Dikeos, D.G., Paparrigopoulos, T.J. (2000). Athens Insomnia Scale:Validation of an instrument based on ICD-10 criteria.J.Psychosom. Res., 48,555-600.

32. Soldatos, C.R., Dikeos, D.G., Paparrigopoulos, T.J. (2002). The diagnostic validity of the Athens Insomnia Scale.J.Psychosom. Res., 55, 263-267.

33. Spitzer,R.L., \&Williams,J.B. \& Kroenke, K. (2001).The PHQ-9.Validity of a Brief Depression Severity Measure.J Gen Intern Med.32,345-359.

34. Spoorthy, M. S., Pratapa, S. K., Mahantc, S. (2020). Mental health problems faced by healthcare workers due to the COVID-19 pandemic-a review. Asian J.Psychiatry.https://doi.org/10.1016/j.ajp.2020.102119

35. Sun, N, Wei, L., Shi, S., Jiao, D., Song, R., Ma, L., ...Wang, H. (2020). A qualitative study on the psychological experience of caregivers of COVID-19 patients. American Journal of Infection Control, 48, 592-598. doi:10.1016/

\section{j.ajic.2020.03.018}

36. Tomlin, J., Dalgleish-Warburton, B. \& Lamph G. (2020). Psychosocial Support for Healthcare Workers During the COVID-19 Pandemic. Front Psychol., 11 , 1960.doi:10.3389/fpsyg.2020.01960

37. Tu, Z., He, J. W., \& Zhou, N. (2020). Sleep quality and mood symptoms in conscripted frontline nurse in Wuhan, China during COVID-19 outbreak: $A$ cross-sectional study. Medicine, 99, e20769. doi:10.1097/MD. 0000000000020769

38. Veenema,T. G.\& Meyer,D. (2020). Why America's nurses were not prepared for the coronavirus pandemic. Retrieved from https://www.forbes.com/sites/ coronavirusfrontlines/2020/06/04/why-americas-nurses-were-notprepared-for-the-coronavirus-pandemic/\#7bfa9a24164b

39. Wang, W., Song, W., Xia, Z., He, Y., Tang, L., Hou, J., \& Lei, S. (2020). Sleep Disturbance and Psychological Profiles of Medical Staff and Non-Medical Staff During the Early Outbreak of COVID-19 in Hubei Province, China. Front. Psychiatry, 11,733. doi: 10.3389/fpsyt.2020.00733

40. Wasim, T., Raana, G. e., Bushra, N., \& Riaz, A. (2020). Effect of COVID-19 Pandemic on Mental Wellbeing of Healthcare Workers in Tertiary Care Hospital.Annals of King Edward Medical University, 26(Special Issue), 140-144. Retrievedfrom https://www.annalskemu.org/journal/index.php/ annals/ article/view/3625

41. Xiao, H., Zhang, Y., Kong, D., Li, S., \& Yang, N. (2020). The Effects of Social Support on Sleep Quality of Medical Staff Treating Patients with Coronavirus Disease 2019 (COVID-19) in January and February 2020 in China. Medical science monitor: international medical journal of experimental and clinical research,26, e923549.https://doi.org/10.12659/MSM.923549

42. Zimet, G. D., Dahlem, N. W., Zimet, S. G., \& Farley, G. K. (1988). The Multidimensional Scale of Perceived Social Support. Journal of Personality Assessment, 52,30-41. 